\title{
Antiphospholipid Antibodies and Renal Involvement
}

\author{
Antonietta Gigante ${ }^{\mathrm{a}}$ Maria Ludovica Gasperini ${ }^{\mathrm{b}}$ Rosario Cianci ${ }^{\mathrm{a}}$ \\ Biagio Barbano ${ }^{a}$ Konstantinos Giannakakis ${ }^{c}$ Domenico Di Donato ${ }^{a}$ \\ Giorgio Fuiano $^{d}$ Antonio Amoroso ${ }^{b}$
}

Departments of a Nephrology, ${ }^{b}$ Clinical Medicine and ${ }^{\mathrm{C} E x p e r i m e n t a l ~ M e d i c i n e ~ a n d ~ P a t h o l o g y, ~ U n i v e r s i t y ~ o f ~ R o m e ~}$ La Sapienza, Rome, and d Department of Nephrology, University of Magna Graecia, Catanzaro, Italy

\section{Key Words}

Antiphospholipid antibodies · Antiphospholipid

syndrome $\cdot$ Systemic lupus erythematosus nephritis •

Antiphospholipid syndrome nephropathy

\begin{abstract}
Antiphospholipid antibodies are a heterogeneous group of autoantibodies associated with the hypercoagulable state affecting all vascular districts with thrombosis named antiphospholipid syndrome (APS). APS is an autoimmune disease with multifactorial etiology that includes cellular, molecular, genetic and pathogenic mechanisms. The APS clinical features are a combination of arterial and/or venous thrombosis, hematological events, recurrent fetal losses, neurological disorders and intra-abdominal manifestations. The renal involvement is associated with both primary and secondary APS. Clinical features include hypertension, renal artery stenosis, thrombotic microangiopathy and other histological manifestations of the nephropathy (APSN), venous renal thrombosis, APSN in the course of systemic lupus erythematosus and renal failure. APSN is an independent risk factor that should be included in the classification criteria for definite APS with characteristic clinical and histological features.

Copyright $\odot 2009$ S. Karger AG, Basel
\end{abstract}

\section{Introduction}

Antiphospholipid antibodies (aPL) are a heterogeneous group of autoantibodies associated with the hypercoagulable state affecting all segments of the vascular bed with thrombosis named antiphospholipid syndrome (APS) $[1,2]$.

The clinical features found in the course of APS include a combination of arterial and/or venous thrombosis, hematological events, recurrent fetal losses or other obstetric manifestations, neurological disorders and intra-abdominal manifestations [3].

The types of aPL that cross-react with anionic phospholipids are anticardiolipin $(\mathrm{aCL})$, antiphosphatidic acid, antiphosphatidylserine, antiphosphatidylinositol and antiphosphatidylglycerol antibodies, while antibodies directed against neutral phospholipids are antiphosphatidylcholine and antiphosphatidylethanolamine [4].

Furthermore, these antibodies use $\beta_{2}$-glycoprotein-Ilike cofactor, having an important role in the thrombotic events, especially in arterial thrombosis in patients with systemic lupus erythematosus (SLE) and APS [5].

APS is considered an autoimmune disease with multifactorial etiology that includes cellular, molecular, genetic and pathogenic mechanisms $[3,6,7]$, and the most important are:

\section{KARGER}

Fax +41613061234

E-Mail karger@karger.ch

www.karger.com (c) 2009 S. Karger AG, Basel

0250-8095/09/0305-0405\$26.00/0

Accessible online at:

www.karger.com/ajn
Dr. Antonietta Gigante, MD

Department of Nephrology, First Faculty of Medicine

University of Rome La Sapienza, Viale dell'Università, 37

IT-00185 Rome (Italy)

Tel./Fax +39 064997 2074, E-Mail antonietta_gigante@yahoo.it 
(1) pathogenetic pathway and activation of the endothelium by aPL associated with a higher secretion of cytokines and activated prostacyclin metabolism;

(2) an oxidant-mediated injury by low-density lipoproteins and macrophages on the vascular endothelium and the possible cross-reaction with aCL;

(3) aPL interference with coagulation state: role of $\beta_{2}$-glycoprotein I as a natural anticoagulant [8];

(4) 'triggering' hypothesis: some infections, through molecular mimicry, may induce an increase in the clinical manifestations of aPL and APS [9].

\section{Classification}

The APS (Hughes's syndrome) is classified as primary APS without other autoimmune disease [10], secondary APS when other autoimmunity disorders occur, like SLE and other connective-tissue diseases, and catastrophic APS (Asherson's syndrome) characterized by rapid chronological occlusive events, shock, respiratory distress syndrome and multiorgan failure [11].

Primary APS may have a heterogeneous clinical presentation such as recurrent thrombosis, obstetric and fetal manifestations, central nervous system, hematological, osteoarticular, cardiopulmonary, adrenal, dermatological, ophthalmological, ear, nose and throat and intra-abdominal involvement (table 1).

The most frequent clinical features in the course of APS are deep venous thrombosis, stroke, pulmonary embolism, superficial thrombophlebitis, transient ischemic attacks and obstetric manifestations.

However, other clinical manifestations, considered minor criteria in the latest classifications, are moderate thrombocytopenia, livedo reticularis, migraine, heart valve thickening or dysfunction, epilepsy, myocardial infarction and amaurosis fugax $[2,12]$.

During APS some symptoms that reflect central nervous system involvement, such as myelitis and sensory disorders, may be mistaken for multiple sclerosis [13].

To define APS, at least 1 clinical and 1 laboratory criterion are necessary [14] (table 2).

\section{Renal Manifestations}

The renal manifestations are associated with both primary and secondary APS [15], and the clinical features include: hypertension, renal artery stenosis (RAS), thrombotic microangiopathy (TMA) and other histological

Table 1. Clinical presentation of APS

Thrombosis

Deep-vein thrombosis

Superficial thrombophlebitis

Arterial thrombosis

\section{Cardiopulmonary}

Pulmonary embolism

Pulmonary hypertension

Pulmonary microthrombosis

Myocardial infarction

Angina

Valve thickening/

dysfunction, vegetations

Myocardiopathy
Obstetric and fetal manifestations Pre-eclampsia

Eclampsia

Early fetal losses ( $<10$ weeks)

Late fetal losses ( $>10$ weeks)

Neurological/psychiatric

Strokes and transient ischemic attack

Migraine and headache

Memory loss

Epilepsy

Chorea

Cerebellar ataxia

Transverse myelopathy

Multi-infarct dementia

Depression

Psychosis

\begin{tabular}{|c|c|}
\hline $\begin{array}{l}\text { Osteoarticular } \\
\text { Arthralgia } \\
\text { Arthritis } \\
\text { Avascular necrosis of bone } \\
\text { Bone fractures }\end{array}$ & $\begin{array}{l}\text { Ophthalmological } \\
\text { Amaurosis fugax } \\
\text { Retinal artery thrombosis } \\
\text { Optic neuropathy }\end{array}$ \\
\hline $\begin{array}{l}\text { Renal } \\
\text { Hypertension } \\
\text { Renal artery stenosis } \\
\text { APS nephropathy } \\
\text { Renal venous thrombosis }\end{array}$ & $\begin{array}{l}\text { Intra-abdominal } \\
\text { Mesenteric ischemia } \\
\text { Budd-Chiari syndrome } \\
\text { Splenic infarction }\end{array}$ \\
\hline $\begin{array}{l}\text { Dermatological } \\
\text { Livedo reticularis } \\
\text { Ulcers/gangrene } \\
\text { Pseudovasculitic lesions } \\
\text { Splinter hemorrhage }\end{array}$ & $\begin{array}{l}\text { Ear, nose and throat } \\
\text { Ménière's disease } \\
\text { Vertigo } \\
\text { Nasal septum perforation }\end{array}$ \\
\hline $\begin{array}{l}\text { Hematological } \\
\text { Thrombocytopenia } \\
\text { Hemolytic anemia }\end{array}$ & $\begin{array}{l}\text { Adrenal } \\
\text { Acute insufficiency }\end{array}$ \\
\hline
\end{tabular}

manifestations of the APS nephropathy (APSN), venous renal thrombosis, APSN in the course of SLE and renal failure [16].

\section{Hypertension}

Hypertension is the most frequent clinical feature described in the course of APS and often appears in association with livedo reticularis, especially when blood pressure is difficult to control suggesting a renovascular mechanism [17].

Because laboratory findings like urinalysis, serum urea and creatinine are normal, a glomerular filtration 
Table 2. Diagnostic criteria for APS

APS is present if at least 1 of the clinical criteria and 1 of the laboratory criteria that follow are met

Clinical

(1) Vascular thrombosis ${ }^{1}$

One or more clinical episodes of arterial, venous or small-vessel thrombosis, in any tissue or organ. Thrombosis must be confirmed by objective validated criteria (i.e. unequivocal findings of appropriate imaging studies or histopathology).

For histopathological confirmation, thrombosis should be present without significant evidence of inflammation in the vessel wall

(2) Pregnancy morbidity ${ }^{2}$

(a) One or more unexplained deaths of a morphologically normal fetus at or beyond the 10th week of gestation, with normal fetal morphology documented by ultrasound or by direct examination of the fetus, or defined according to standard definitions

(b) One or more premature births of a morphologically normal neonate before the 34th week of gestation because of: (i) eclampsia or severe preeclampsia or (ii) recognized features of placental insufficiency

(c) Three or more unexplained consecutive spontaneous abortions before the 10th week of gestation, with maternal anatomical or hormonal abnormalities and paternal and maternal chromosomal causes excluded

Laboratory criteria ${ }^{3}$

(1) Lupus anticoagulant present in plasma, on 2 or more occasions at least 12 weeks apart, detected according to the guidelines of the International Society on Thrombosis and Haemostasis (Scientific Subcommittee on lupus anticoagulants/phospholipiddependent antibodies)

(2) aCL antibody of IgG and/or IgM isotype in serum or plasma, present in medium or at high titer (i.e. $>40$ GPL or MPL, or above the 99th percentile), on 2 or more occasions, at least 12 weeks apart, measured by a standardized ELISA

(3) Anti- $\beta_{2}$-glycoprotein-I antibody of IgG and/or IgM isotype in serum or plasma (at titers above the 99th percentile), present on 2 or more occasions, at least 12 weeks apart, measured by a standardized ELISA, according to recommended procedures

$\mathrm{GPL}=$ Units for IgG; MPL = units for IgM.

${ }^{1}$ Classification of APS should be avoided if less than 12 weeks or more than 5 years separate the positive aPL test and the clinical manifestation.

2 Two subgroups of APS patients should be recognized, according to (a) the presence and (b) the absence of additional risk factors for thrombosis. Such indicative (but not exhaustive) factors include: age ( $>55$ in men and $>65$ in women), the presence of any of the established risk factors for cardiovascular disease (hypertension, diabetes mellitus, elevated low-density lipoprotein or low high-density lipoprotein cholesterol, cigarette smoking, family history of premature cardiovascular disease, body mass index $>30$, microalbuminuria, estimated glomerular filtration rate $<60$ $\mathrm{ml} \mathrm{min}^{-1}$ ), inherited thrombophilias, oral contraceptives, nephrotic syndrome, malignancy, immobilization and surgery. Thus, patients who fulfil criteria should be stratified according to contributing causes of thrombosis. A thrombotic episode in the past could be considered as a clinical criterion, provided that thrombosis is proved by appropriate diagnostic means and that no alternative diagnosis or cause of thrombosis is found. Superficial venous thrombosis is not included in the clinical criteria. Generally accepted features of placental insufficiency include: (i) abnormal or nonreassuring fetal surveillance test(s), e.g. a nonreactive nonstress test, suggestive of fetal hypoxemia, (ii) abnormal Doppler flow velocimetry waveform analysis suggestive of fetal hypoxemia, e.g. absent end-diastolic flow in the umbilical artery, (iii) oligohydramnios, e.g. an amniotic fluid index of $5 \mathrm{~cm}$ or less, or (iv) a postnatal birth weight less than the 10th percentile for the gestational age.

${ }^{3}$ In studies of populations of patients who have more than 1 type of pregnancy morbidity, investigators are strongly encouraged to stratify groups of subjects according to the following categories: $\mathrm{I}=$ more than 1 laboratory criterion present (any combination); IIa = lupus anticoagulant present alone; IIb = aCL antibody present alone; IIc $=$ anti- $\beta_{2}$-glycoprotein-I antibody present alone. rate, urine sediment, 24-hour urinary protein excretion, renal ultrasound and scintigraphy are more sensitive to diagnose early APSN [16].

Nochy et al. [18] documented systemic hypertension as the main clinical sign of nephropathy in $93 \%$ of patients with primary APS, often secondary to vascular lesions (arteriosclerosis, fibrous intimal hyperplasia, arterial and arteriolar fibrous and fibrocellular occlusions, TMA).
High blood pressure and renal failure were described by Kleinknecht et al. [19] in all SLE patients with APS. It is well established that hypertension is a common complication of APS and it could be difficult to treat; in the presence of microthrombi, blood pressure control and anticoagulant therapy may improve renal function [20]. 


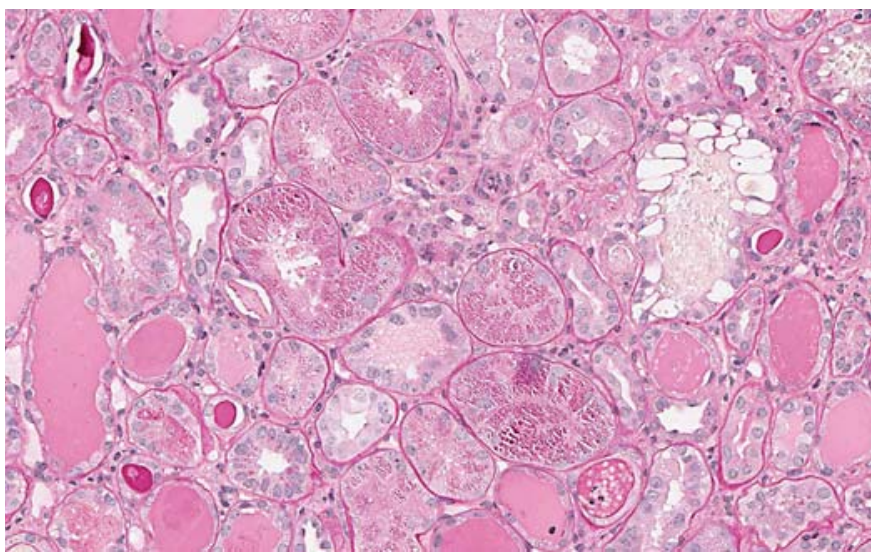

Fig. 1. The proximal tubules contain protein resorption droplets; there is a moderate dilatation of the tubules containing hyaline casts. PAS. $\times 100$.

\section{Renal Artery Stenosis}

RAS is one of the first manifestations of APS with important clinical consequences [21]. Sangle et al. [22] demonstrated the presence of RAS in $26 \%$ of 77 patients with aPL and uncontrolled blood pressure (60 with SLE and APS, 11 with primary APS, 6 with aPL only). They observed two possible patterns regarding stenotic artery lesions. The most represented pattern was smooth, welldefined and noncritical stenosis distal to the renal artery ostium; these findings are different from atherosclerotic and fibromuscular dysplasia-related lesions. Indeed, the other described pattern seems to be similar to atherosclerotic lesions and founded in the proximal region to the ostium of the renal artery, sometimes involving the aorta [22].

Arterial and venous thrombosis are well documented in the kidney, and a high prevalence of RAS in the course of APS suggests a physiopathological relation with the prothrombotic state. Furthermore, aPL plays an important role in accelerated atherosclerosis, as a severe risk factor [23, 24]; moreover, aCL may cross-react with oxidized low-density lipoprotein $[25,26]$.

Atsumi et al. [27] have also described, in many APS patients with arteriolar lesions, the pathogenic role of high levels of endothelin 1 in a vasoconstrictive mechanism.

In the literature many data suggest that oral anticoagulation may strengthen the treatment, especially in patients developing intrastent restenosis. Anticoagulant therapy may play a role to stabilize or improve the steno-

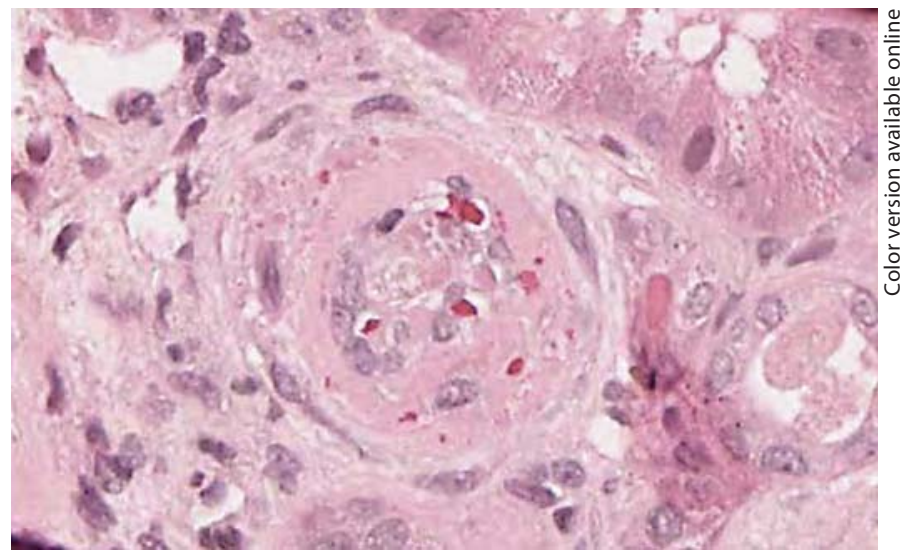

Fig. 2. TMA in a patient with lupus nephritis WHO class IV. A section of an arteriole with fibrinoid necrosis, thrombosis and intramural entrapment of whole and fragmented erythrocytes. HE. $\times 200$.

sis, to prevent the presence of restenosis after angioplasty and as prophylaxis against thrombotic events in other vascular districts.

In conclusion, thrombosis may be the starting point for the development of RAS in hypertensive and uncontrolled blood pressure patients with APS.

Renal outcome may improve targeting an international normalized ratio (INR) of 3-4.5 and tightly monitoring anticoagulation therapy [28].

\section{APS Nephropathy}

APSN is characterized by vascular involvement associated with hypertension, acute and/or chronic renal failure and low-grade proteinuria (fig. 1).

Biopsy-proven renal lesions are statistically related to lupus anticoagulant (LAC), but not with aCL, and their presence and severity represent independent risk factors to develop hypertension, elevated serum creatinine and increased interstitial fibrosis [29]. Furthermore, in the course of APSN, extrarenal signs such as renal arterial (but not venous) thrombosis are associated with APS [30].

APSN vascular lesions may be acute (TMA) and/or chronic (arteriosclerosis, arterial fibrous intimal hyperplasia, tubular thyroidization, arteriolar occlusions and focal cortical atrophy) [18].

TMA is determined by fibrin thrombi in glomeruli and in the whole intrarenal vascular tree, without inflammatory cells or vascular immune deposits. In fact, by immunofluorescence study, fibrin is the main constitu- 


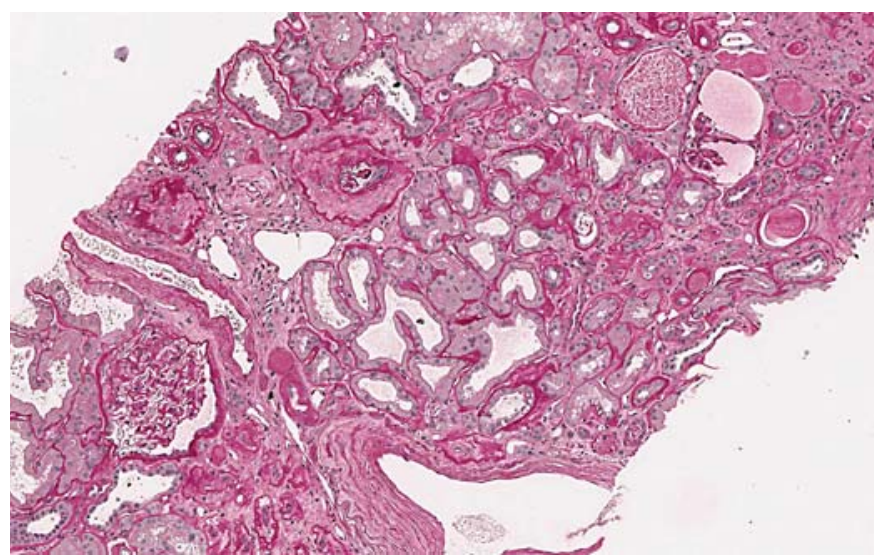

Fig. 3. Variable intimal fibrosis of the arteries, arteriolar hyalinosis. There is also interstitial fibrosis, tubular atrophy and dilatation. PAS. $\times 100$.

ent of thrombi, in the absence of immunoglobulins (fig. 2).

Arteriosclerosis and arteriolosclerosis are characterized by fibrous intimal thickening associated with arteriolar hyalinosis that reduces the vascular lumen of arcuate and interlobular arteries.

Fibrous intimal hyperplasia is different from that observed as a consequence of aging arteriosclerosis, because cellular proliferation is more intense. The myofibroblastic intimal cellular proliferation leads to intima thickening, with tortuosity of interlobular arteries and their branches.

The media shows two different patterns: proliferative with hypertrophic myocytes or, alternatively, atrophic and fibrous. The lumen is often reduced by areas of fibrous thickening of intima or recanalizing thrombosis (fig. 3).

Fibrocellular and fibrous arterial and arteriolar occlusions are often present in small interstitial arteries (fig. 4).

Focal cortical atrophy involves superficial zones of the subcapsular cortex, associated with a depression of the contour of the renal capsule. In the regions involved by focal cortical atrophy, the glomeruli can appear small and sclerotic or, in contrast, pseudocystic and voluminous, often clustered in groups, sometimes in the same biopsy. Focal cortical atrophy is considered to be very typical of APSN and leads to dense interstitial fibrosis, with thyroidization and tubular atrophy. It can often be seen associated with the vascular lesions of fibrous intimal hyperplasia. Immunofluorescence can reveal fibrin and more inconstantly C3 and IgM deposits in the vessels

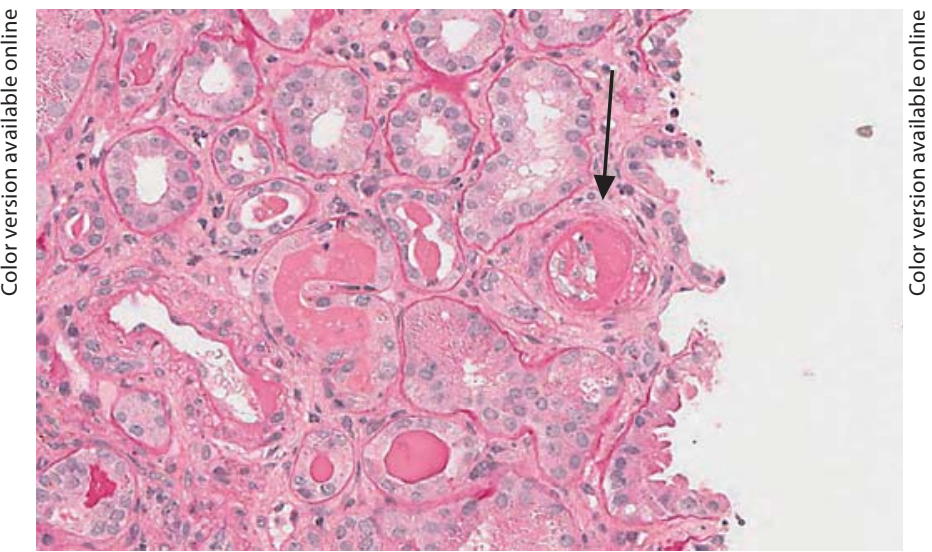

Fig. 4. Complete arteriolar occlusion due to severe intimal hyalinosis (arrow). PAS. $\times 200$.

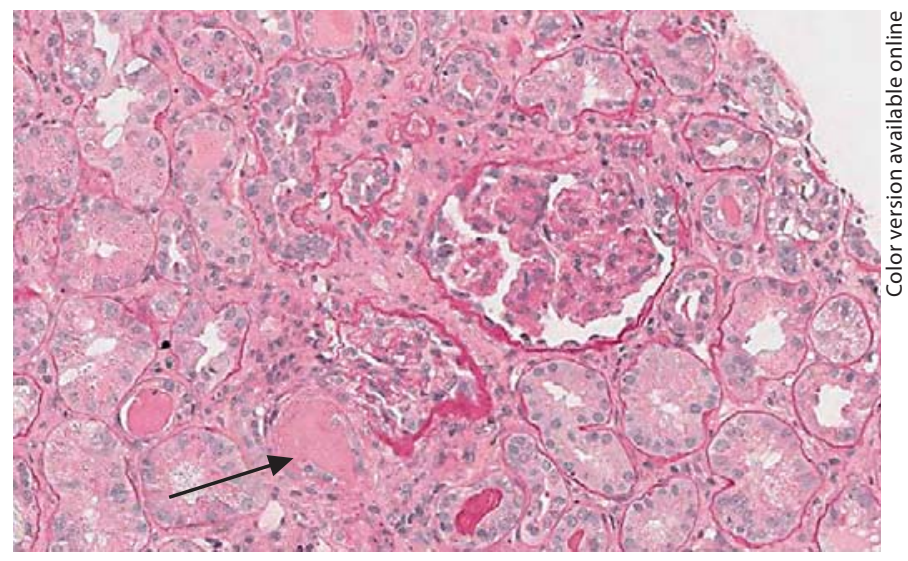

Fig. 5. Focal atrophic area: there is global wrinkling and thickening of glomerular basement membranes. Bowman's capsule is thickened. There is interstitial fibrosis and tubular atrophy. Fibrinoid change in the arteriolar wall (arrow). PAS. $\times 100$.

showing thickening; sometimes, renin deposits may be observed in the juxtaglomerular apparatus (fig. 5).

Tubular thyroidization is characterized by tubular atrophy, with eosinophilic casts, resembling thyroid tissue, often in the deep cortex or medulla.

However, in a few cases it is possible to distinguish other pathological variants of APSN, resembling membranous nephropathy, minimal-change disease, focal segmental glomerulosclerosis, segmental glomerulosclerosis, mesangial C3 nephropathy and pauci immune crescentic glomerulonephritis [15]. 


\section{Renal Venous Thrombosis}

Both primary APS and aPL-positive patients with SLE nephritis are prone to develop thrombosis of the renal veins and inferior vena cava, associated with nephrotic-range proteinuria, especially in those with LAC positivity.

\section{aPL Associated with SLE}

In a large series, Tektonidou et al. [31] demonstrated that APSN occurs in $39.5 \%$ of SLE patients with aPL, whilst only in $4.3 \%$ of the SLE patients without aPL. APSN was strongly associated with LAC, aCL and livedo reticularis. In serial kidney biopsies, it was possible to find both acute and chronic lesions, such as fibrotic, proliferative and obstructive lesions due to thrombotic changes [31]. The renal prognosis in SLE patients worsens in the presence of APSN. The severity of renal SLE is related neither to APSN nor to the WHO classes of lupus glomerulopathy [30].

In SLE patients the presence of aCL is related to a greater degree of sclerosis, crescent formation and necrosis of glomeruli $[32,33]$.

The clinical presentation of SLE patients with aCL includes hypertension from mild to malignant, hematuria, proteinuria from mild to nephrotic range, and acute or chronic renal insufficiency.

The bioptic distinction between APSN and SLE nephropathy is helpful to decide on the appropriate therapy, choosing only anticoagulants in APSN patients and cytotoxic agents in the course of lupus nephritis [34].

\section{End-Stage Renal Disease and Renal Transplantation}

End-stage renal disease is an uncommon feature in the course of primary APS [15].

It has been well documented that the frequency of aPL in patients undergoing hemodialysis for unknown causes of renal failure is higher as compared to the general population.

No correlation between these antibodies and age, length of time on dialysis, sex, infections, drugs or type of dialysis membrane was found [34, 35].

The exact role of aPL in end-stage renal disease is unknown, but some studies have reported associations between aPL and vascular access thrombosis [36].

Several investigations have reported that both $\mathrm{aCL}$ and LAC increase the risk of vascular access thrombosis; oth- er studies suggest that thrombotic events are associated only with LAC [37].

There is evidence that in patients undergoing renal transplantation, aPL positivity correlates with a high frequency of vascular thrombosis, graft failure and systemic coagulation disorders, even if these patients were treated with anticoagulant therapy $[15,38]$.

\section{Management}

The APS management is based on four classes of drugs: aspirin, heparin, warfarin and immunosuppressive drugs.

In a meta-analysis, Lim et al. [39] proposed an algorithm for antithrombotic treatment of patients with anthiphospholipid antibodies, in relation to the presence or absence of prior thrombosis and fetal loss, balancing the bleeding risk against antithrombotic effects.

In nonpregnant patients without prior thrombosis, no treatment or low-dose aspirin is required; otherwise, pregnancy suggests a prophylactic therapy with unfractionated heparin or low-molecular-weight heparin plus aspirin, particularly in the presence of prior pregnancy loss.

Venous thromboembolism is the most frequent clinical feature, and treatment consists of initial unfractionated or low-molecular-weight heparin for at least 5 days.

The first thrombotic episode or thrombosis recurrences (both venous and arterial) need a long-term anticoagulant therapy, targeting an INR of 2.0-3.0. Instead, cerebral artery thrombosis requires long-term anticoagulant therapy with a lower INR (1.4-2.8) or long-term aspirin treatment.

Furthermore, the association of APS with SLE justifies an immunosuppressive therapy such as cyclophosphamide.

In the presence of catastrophic APS, immunosuppressants, intravenous immunoglobulins or plasma exchange may offer help as rescue therapy.

In the literature the use of rituximab, an anti-CD20 monoclonal antibody, is reported in selected patients. However, clinical trials are needed to evaluate the clinical indication of rituximab in APS patients [13, 40].

\section{Conclusion}

APSN should be included in the classification criteria for defining APS. 
The more frequent manifestations of APS are renal artery thrombosis or RAS, renal infarction, renal vein thrombosis and end-stage renal disease.

Clinically, APSN is characterized by a vascular nephropathy characterized by hypertension, low-grade proteinuria, and acute and/or chronic renal insufficiency.

Furthermore, aPL testing should be considered in nonaged patients with RAS, high blood pressure and unexplainable deterioration of renal function. In these patients renal outcome may improve with anticoagulant therapy targeted to keep an INR between 3 and 4.5.

Histological findings are TMA as acute thrombosis and fibrous intimal hyperplasia, arteriosclerosis and fo- cal cortical atrophy, arterial and arteriolar fibrous and fibrocellular occlusions, and tubular thyroidization as chronic vascular lesions. Biopsy-proven renal lesions are statistically related to LAC, but not with aCL, and are helpful to predict the development of hypertension, renal insufficiency and progressive interstitial fibrosis.

In conclusion, in SLE patients with positivity for aPL, renal involvement may be due to connective tissue diseases or APS, the correct diagnosis of which can be very important to establish a correct therapeutic approach and improve the outcome.

\section{References}

1 Hughes GRV: Thrombosis, abortion, cerebral disease and lupus anticoagulant. BMJ 1983;287:1088-1089.

12 Cervera R: Lessons from the 'Euro-Phospholipid' project. Autoimmun Rev 2008; 7:174178.

-3 Atanassova PA: Antiphospholipid syndrome and vascular ischemic (occlusive) diseases: an overview. Yonsei Med J 2007;48:901926.

4 Carreras LO, Forastiero RR, Martinuzzo ME: Which are the best biological markers of the antiphospholipid syndrome? J Autoimmun 2000;15:163-172.

-5 Lopez LR, Dier KJ, Lopez D, Merrill JT, Fink CA: Anti- $\beta_{2}$-glycoprotein I and antiphosphatidylserine antibodies are predictors of arterial thrombosis in patients with antiphospholipid syndrome. Am J Clin Pathol 2004;121:142-149.

6 Rand JH: Molecular pathogenesis of the antiphospholipid syndrome. Circ Res 2002;90: 29-37.

-7 Giannakopoulos B, Passam F, Rahgozar S, Krilis SA: Current concepts on the pathogenesis of the antiphospholipid syndrome. Blood 2007; 109:422-430.

8 Sherer Y, Berkun Y, Blank M, Shoenfeld Y: Pathogenesis of the antiphospholipid syndrome. Pediatr Rheumatol Online J 2004;2: 492-496.

-9 Shoenfeld Y, Blank M, Cervera R, Font J, Raschi E, Meroni PL: Infectious origin of the antiphospholipid syndrome. Ann Rheum Dis 2006;65:2-6.

10 Asherson RA, Cervera R, Piette JC, Shoenfeld Y: The antiphospholipid syndrome: history, classification, and differential diagnosis; in Asherson RA, Cervera R, Piette JC, Shoenfeld Y (eds): The Antiphospholipid Syndrome. Boca Raton, CRC Press, 1996, pp $3-12$.

\section{Bucciarelli S, Espinosa G, Cervera R, et al: European Forum on Antiphospholipid Anti- bodies - mortality in the catastrophic an- tiphospholipid syndrome: causes of death and prognostic factors in a series of $250 \mathrm{pa}-$ tients. Arthritis Rheum 2006;54:2568-2576.}

12 Miyakis S, Lockshin MD, Atsumi T, Branch DW, Brey RL, Cervera R, et al: International consensus statement on an update of the classification criteria for definite antiphospholipid syndrome (APS). J Thromb Haemost 2006;4:295-306.

$>13$ Edwards CJ, Hughes GR: Hughes syndrome (the antiphospholipid syndrome): 25 years old. Mod Rheumatol 2008;18:119-124.

14 Wilson WA, Gharavi AE, Koike T, Lockshin MD, Branch DW, Piette JC, et al: International consensus statement on preliminary classification criteria for definite antiphospholipid syndrome: report of an international workshop. Arthritis Rheum 1999;42: 1309-1311.

15 Uthman I, Khamashta M: Antiphospholipid syndrome and the kidneys. Semin Arthritis Rheum 2006;35:360-367.

16 D'Cruz DP: Renal manifestations of the antiphospholipid syndrome. Lupus 2005; 14 : 45-48.

17 Hughes GR: The Prosser-White oration 1983: connective tissue disease and the skin. Clin Exp Dermatol 1984;9:535-544.

18 Nochy D, Daugas E, Droz D, Beaufils H, Grunfeld JP, Piette JC, et al: The intrarenal vascular lesions associated with primary antiphospholipid syndrome. J Am Soc Nephrol 1999;10:507-518.

19 Kleinknecht D, Bobrie G, Meyer O, Noel LH, Callard P, Ramdane M: Recurrent thrombosis and renal vascular disease in patients with a lupus anticoagulant. Nephrol Dial Transplant 1989;4:854-858.
20 Dayal NA, Isenberg DA: End stage renal failure in primary antiphospholipid syndrome - case report and review of literature. Rheumatology (Oxford) 2003;42:11281129.

21 Sangle SR, D'Cruz DP: Renal artery stenosis: a new facet of the antiphospholipid (Hughes) syndrome. Lupus 2003;12:803-804.

22 Sangle SR, D'Cruz DP, Jan W, Karim MY, Khamashta MA, Abbs IC, Hughes GRV: Renal artery stenosis in the antiphospholipid (Hughes) syndrome and hypertension. Ann Rheum Dis 2003;62:999-1002.

-23 Rysava R, Zabka J, Peregrin JH, Tesar V, Merta M, Rychlik I: Acute renal failure due to bilateral renal artery thrombosis associated with primary antiphospholipid syndrome. Nephrol Dial Transplant 1998;13: 2645-2647.

24 Morgan RJ, Feneley RC: Renal vein thrombosis caused by primary antiphospholipid syndrome. Br J Urol 1994;74:807-808.

25 Vaarala O, Alfthan G, Jauhiainen M, Leirisalo-Repo M, Aho KND, Palosuo T: Crossreaction between antibodies to oxidized lowdensity lipoprotein and to cardiolipin in systemic lupus erythematosus. Lancet 1993; 341:923-925.

26 Hasunuma Y, Matsura E, Makita Z, Katahira T, Nishi S, Koike T: Involvement of $\beta_{2}$-glycoprotein I and anticardiolipin antibodies in oxidatively modified low density lipoprotein uptake by macrophages. Clin Exp Immunol 1997; 107:569-574.

27 Atsumi T, Khamashta MA, Haworth RS, Brooks G, Amengual O, Ichikawa K, et al: Arterial disease and thrombosis in the antiphospholipid syndrome, a pathogenic role for endothelin 1. Arthritis Rheum 1998;41: 800-807. 
-28 Sangle SR, D’Cruz DP, Abbs IC, Khamashta MA, Hughes GR: Renal artery stenosis in hypertensive patients with antiphospholipid (Hughes) syndrome: outcome following anticoagulation. Rheumatology (Oxford) 2005; 44:372-377.

-29 Fakhouri F, Noël LH, Zuber J, Beaufils H, Martinez F, Lebon P, Papo T, Chauveau D, Bletry O, Grünfeld JP, Piette JC, Lesavre P: The expanding spectrum of renal diseases associated with antiphospholipid syndrome. Am J Kidney Dis 2003;41:1205-1211.

-30 Daugas E, Nochy D, Huong DLT, Duhaut P, Beaufils HLN, Caudwell V, Bariety J, Piette JC, Hill G: Antiphospholipid syndrome nephropathy in systemic lupus erythematosus. J Am Soc Nephrol 2002;13:42-52.

-31 Tektonidou MG, Sotsiou F, Nakopoulou L, Vlachoyiannopoulos PG, Moutsopoulos HM: Antiphospholipid syndrome nephropathy in patients with systemic lupus erythematosus and antiphospholipid antibodies: prevalence, clinical associations, and longterm outcome. Arthritis Rheum 2004;50: 2569-2579.
32 Moss KE, Isenberg DA: Comparison of renal disease severity and outcome in patients with primary antiphospholipid syndrome, antiphospholipid syndrome secondary to systemic lupus erythematosus (SLE) and SLE alone. Rheumatology (Oxford) 2001;40:863867.

33 Bhandari S, Harnden P, Brownjohn AM, Turney JH: Association of anticardiolipin antibodies with intraglomerular thrombi and renal dysfunction in lupus nephritis. Q J Med 1998;91:401-409.

34 Coggins HC, McCluskey RT: Case records of the Massachusetts General Hospital - weekly clinicopathological exercises. Case 112001: rapidly progressive renal failure in a 35-year-old woman with systemic lupus erythematosus. N Engl J Med 2001;344:11521158 .

35 Gronhagen-Riska C, Teppo AM, Helantera A, Honkanen E, Julkunen H: Raised concentrations of antibodies to cardiolipin in patients receiving dialysis. BMJ 1990;300: 1696-1697.
36 Haviv YS: Association of anticardiolipin antibodies with vascular access occlusion in hemodialysis patients: cause or effect? Nephron 2000;86:447-454.

37 Chew SL, Lins RL, Daelemans R, Zachee P, De Clerck LS, Vermylen J: Are antiphospholipid antibodies clinically relevant in dialysis patients? Nephrol Dial Transplant 1992;7: 1194-1198.

38 Wagenknecht DR, Fastenau DR, Torry RJ, Becker DG, LeFor WM, Carter CB, et al: Risk of early renal allograft failure is increased for patients with antiphospholipid antibodies. Transplant Int 2000;13:S78-S81

39 Lim W, Crowther MA, Eikelboom JW: Management of antiphospholipid antibody syndrome: a systematic review. JAMA 2006;295: 1050-1057.

40 Erre GL, Pardini S, Faedda R, Passiu G: Effect of rituximab on clinical and laboratory features of antiphospholipid syndrome: a case report and a review of literature. Lupus 2008; 17:50-55. 